$\begin{array}{ll} & \text { Etnográfica } \\ \text { etnográfica } & \text { Revista do Centro em Rede de Investigação em }\end{array}$

Antropologia

vol. 11 (2) | 2007

Vol. 11 (2)

\title{
Este obscuro objecto do desejo etnográfico: o
}

museu

Jean-Yves Durand

\section{(2) OpenEdition}

Journals

\section{Edição electrónica}

URL: https://journals.openedition.org/etnografica/2024

DOI: 10.4000/etnografica.2024

ISSN: 2182-2891

\section{Editora}

Centro em Rede de Investigação em Antropologia

\section{Edição impressa}

Data de publição: 1 novembro 2007

Paginação: 373-386

ISBN: 0873-6561; E-ISBN 2182-2891

ISSN: 0873-6561

\section{Refêrencia eletrónica}

Jean-Yves Durand, «Este obscuro objecto do desejo etnográfico: o museu», Etnográfica [Online], vol. 11 (2) | 2007, posto online no dia 27 setembro 2012, consultado o 10 fevereiro 2022. URL: http:// journals.openedition.org/etnografica/2024 ; DOI: https://doi.org/10.4000/etnografica.2024

\section{(c) (†) (8)}

Etnográfica is licensed under a Creative Commons Attribution-NonCommercial 4.0 International License. 


\section{Este obscuro objecto do desejo etnográfico: o museu}

\section{Jean-Yves Durand}

Universidade do Minho (UM, Braga); Centro em Rede de Investigação em Antropologia (pólo UM); Institut D’Ethnologie Méditerranéenne Et Comparative (Aix-en-Provence)

“VITE, MILOU, AU MUSÉE ETHNOGRAPHIQUE!”: QUANDO O TINTIM SAI de casa a correr, no início de A Orelha Quebrada, o seu visível entusiasmo não provém de um particular interesse em exposições ou em colecções de etnografia exótica: acabou de ser anunciado na rádio que durante a noite o museu foi palco de um intrigante assalto e que desapareceu um fetiche muito raro.

Uma parte da atracção operada pela obra de Hergé resulta sem dúvida da sua notável capacidade para dar um valor icónico aos seus desenhos: um carro, um polícia ou um foguetão desenhados por ele não são um carro, um polícia ou um foguetão quaisquer, são $\boldsymbol{o}$ carro, $\boldsymbol{o}$ polícia e $\boldsymbol{o}$ foguetão, quase que arquetipais. Da mesma maneira, nalgumas pinceladas, as imagens da primeira página de A Orelha Quebrada chegam para nos mostrar uma instituição que parece corresponder exactamente à sua imagem mais difundida no imaginário partilhado: monumentalidade da entrada; organização por áreas geográfico-culturais extra-ocidentais; rotulagem descritiva e descontextualizadora; artefactos seleccionados antes de mais por razões estéticas; público burguês contido, cuidadoso (já que as vitrinas são algo estranhamente raras aqui) em não quebrar a distância física, limitando um deleite que só pode ser visual; guarda fardado, detentor de inquestionável autoridade institucional, mas que trata os objectos com a familiaridade de um coleccionador blasé, etc. Em suma, mais ou menos aquilo que um estudante em antropologia formado hoje em dia aprende que um museu etnográfico não deve ser.

Esta aventura do Tintim foi concebida em 1935-37, em pleno período de expedições científicas organizadas por um mundo ocidental que se encontrava 
então no auge do seu poder colonial. Noutras aventuras do Tintim há outras expedições, exclusivamente masculinas, notavelmente colectivas e pluridisciplinares, e em que não falta um "fameux physicien de l'université de Cö̈mbre”. O saber, todo o saber, só podia ser positivo, cumulativo, distanciado. Claude Lévi-Strauss encontrava-se no Brasil; Paul-Émile Victor hibernava na Gronelândia, passando por uma profunda aventura pessoal e realizando uma extraordinária recolha acerca da "civilização da foca" que enriqueceu o acervo do Musée de l'Homme, em Paris. São também os anos em que Marcel Griaule chefiava as suas expedições na África subsariana: Dacar-Djibuti, Sara-Sudão, Sara-Camarões... E é provável que, muitos anos mais tarde, juntamente com a leitura de Tintim, a romantização do etnógrafo em explorador e aventureiro, despreocupado abastecedor de tesouros etnográficos, terá informado as motivações juvenis de mais de um antropólogo profissional de hoje.

O elo epistemológico e institucional entre museus etnográficos e investigação (e também, nalguns casos, ensino) foi patente durante décadas: basta pensar, entre muitos outros exemplos, na presença de Franz Boas ou de Margaret Mead no Museum of Natural History de Nova Iorque, no papel do Musée de l'Homme em Paris, nas ligações entre o Peabody Museum e o Departamento de Antropologia de Harvard. E foi no recém-criado (1901) museu de antropologia da universidade de Berkeley, agora conhecido como Phoebe Hearst Museum of Anthropology, que Alfred Kroeber produziu o essencial da sua duradoura influência, envolvido na realização de uma "etnografia de urgência”. Esta preocupação, motivada sobretudo pelas consequências da colonização do continente norte-americano, destinava-se a registar os testemunhos de "culturas" concebidas como realidades objectivas, cristalizadas em boa parte (embora o ponto de vista de Kroeber a este respeito não fosse simplista) nas suas manifestações materiais. Teve um momento alto quando, um pouco antes da Primeira Guerra Mundial, Edward Sapir se juntou a Kroeber para estudar a língua de Ishi. Supostamente o último dos Yahi, este homem foi acolhido no museu, onde viveu os seus últimos anos. Perante os riscos de contágio a que estava exposto nas demonstrações que fazia para o público, falou-se na possibilidade de apresentar Ishi numa vitrina: é verdade que se tratava de o proteger das doenças, mas uma outra solução teria sido simplesmente não o apresentar. Tem de se dizer que, depois de ter lentamente ultrapassado o medo que tinha das multidões, Ishi gostava de mostrar os seus saberes e nunca manifestou insatisfação com o seu estatuto ou as suas novas condições de existência. Quando faleceu, vítima de tuberculose, na ausência de Kroeber que gozava um ano sabático, o seu corpo foi autopsiado (o que contrariava os seus desejos) e cremado, e o seu cérebro conservado num frasco que o próprio Kroeber, apesar do seu descontentamento inicial, acabou por enviar para a Smithsonian Institution. Em finais dos anos 90, os restos de Ishi foram reivindicados pelos índios Maidu, do norte da Califórnia, no âmbito das leis norte-americanas 
acerca da repatriação de restos humanos e de artefactos abusivamente colectados nos museus e, mais geralmente, da ideologia de reavaliação da autoridade respectiva das comunidades e das instituições que as estudam (ver aqui a contribuição de Anthony Shelton). Foram no entanto entregues, para serem sepultados num sítio mantido secreto, aos membros do vizinho Pit River Tribe, em função de um critério de maior proximidade linguística entre estes e o que se sabe do idioma de Ishi (Scheper-Hugues 2001). Toda esta história, aqui muito resumida (ver, por exemplo, Karl Kroeber e Clifton Kroeber 2003) ilustra em traços por vezes caricaturais as tensões e os paradoxos inerentes ao facto de a museologia etnográfica lidar com matéria humana, viva e dinâmica.

\section{HEGEMONIAS, FRAGMENTAÇÕES, POLÉMICAS}

É sabido que os modelos de museus e de museologia hegemónicos no tempo de Kroeber acabariam por passar pela mesma crítica interna e externa que todo o conjunto dos pressupostos, das condições e das implicações do discurso antropológico, ou mesmo da sua própria natureza, vista como intrinsecamente ligada a posições de dominação. Tal decorreu em parte das novas condições criadas pela descolonização. No caso da etnomuseologia combinou-se também com a emergência, a partir dos anos 60, das ideias (no fundo igualmente ligadas à crítica do saber canónico) que é possível agrupar debaixo das bandeiras da "nova museologia" e dos "ecomuseus": contribuição para um "melhor conhecimento delas próprias" por parte das populações envolvidas, ancoragem territorial, descentralização, interdisciplinaridade, contextualização, promoção do "desenvolvimento sustentado" através da valorização da "identidade", participação em vez de autoridade... (ver o regulamento do Mouvement International pour une Nouvelle Muséologie, em http://minom-icom.net/PDF/Reglementsgeneraux.pdf). Além disso, as especificidades do "património etnográfico" e dos interesses que o rodeiam constituem um terceiro elemento que se veio acrescentar a esta já poderosa dinâmica. É que, ao contrário do que acontece com a arqueologia, a arte, a geologia, a botânica, etc., não é muito difícil elaborar um "museu" que se auto-rotulará de "etnográfico" - de maneira certa ou não do ponto de vista dos investigadores profissionais, é outro assunto. Esta facilidade combinou-se com o facto de, a partir dos anos 70, se ter afirmado na Europa uma valorização do local, uma certa nostalgia, ou até reivindicações de ordem regionalista que, embora de maneira variável consoante os países, se traduziram pela emergência de uma etnografia do-it-yourself (Bromberger 1987: 78) e pela simultânea multiplicação de iniciativas locais de cariz museológico (cf. artigo de C. Bromberger no dossiê).

Em Portugal o fenómeno foi um pouco mais tardio, mas enraizado numa rede bastante densa de "grupos etnográficos" e de ranchos folclóricos e apoiado num antigo e contínuo interesse explicitamente formulado em termos 
de "etnografia" por parte de certas instituições, como o INATEL. O boom das iniciativas patrimoniais (não unicamente no registo etnográfico) deu-se aqui com alguns anos de atraso em relação à Europa mais setentrional, mas com igual vigor: "na primeira década de 2000, verificou-se um fenómeno de aparecimento repentino de museus resultando num total de 43 entidades no Alto Minho" em 2007, quando só havia 18 em 1996, "tendo sido criado 26 $(60,5 \%)$ nestes últimos 10 anos, dos quais 19 (44,2\%) nos últimos 5 anos" (Alpuim 2007: 133, 141-142). Não há dados acerca de outras regiões do país, mas tudo indica que a evolução seria semelhante e que um projecto de constituição de um Roteiro de Museus etnográficos (Dias 1997-2001) encontraria, uns dez anos depois, uma realidade ainda mais extensa para descrever. Será interessante observar nos próximos tempos em que medida esta dinâmica e o tipo de iniciativas serão ou não influenciados pelo considerável sucesso, junto dos políticos e do público, da valorização do "património imaterial", discurso inicialmente propagado pela UNESCO e que tem sido com alguma frequência activado e promovido por antropólogos à escala local, talvez nem sempre sem uma certa imprudência estratégica e, sobretudo, epistemológica.

O que é certo, é que esses "museus de sociedade" (expressão usada em França para designar iniciativas que são muitas vezes de tipo bottom-up e cuja pertença científica pode ser mais ou menos incerta) apresentam uma variedade considerável, por vezes traduzida nos nomes que se dão, e raramente cumprem minimamente as funções museológicas exigidas pela lei-quadro dos museus portugueses (estudo e investigação, incorporação, inventário e documentação, conservação, segurança, educação; Decreto-lei 47/2004 de 19 de Agosto, capítulo II, secção I, artigo $7 .^{\circ}$ ), podendo até nalguns casos nem sequer serem abertos para visita. Não menos certo é o facto de serem a expressão de um vivo "desejo de museu" (Alpuim 2007: 179), muito palpável por quem tem algum contacto com os serviços culturais de Câmaras Municipais ou, no universo rural, com cidadãos envolvidos em projectos de cariz cultural. Entre esta proliferação de iniciativas locais, concretizadas em museus, núcleos museológicos, ecomuseus, pólos, casas-museus, salas-museus, colecções visitáveis, etc., de todos os feitios e tamanhos, e instituições pesadas do tipo do Museu do Quai Branly, o principal ponto comum será talvez serem igualmente considerados como "museus" pelos actores sociais que os rodeiam. Exactamente como certos antropólogos podem achar perturbadora a maneira como se encontra diluída a antiga coerência minimal da sua disciplina, hoje estilhaçada em objectos, métodos, unidades de estudo extremamente diversos (Bromberger 1997), muitos parecem sentir um certo desconforto perante a fragmentação da realidade etnomuseológica contemporânea entre instituições díspares e entre correntes de pensamento aparentemente irreconciliáveis.

Todos sabem que os diversos aspectos da museografia etnológica têm ocupado um lugar central na sua disciplina e contribuíram também muitas vezes 
para a sua institucionalização. Mas a força desta ligação antiga aparece agora em grande medida desactualizada, quando o interesse dos antropólogos pela cultura material diminuiu consideravelmente ou, pelo menos, seguiu orientações novas: a observação dos usos dos artefactos, do consumo, na senda dos material culture studies, substituiu a tradição, outrora dominante, de abordagem formal dos artefactos, da análise da acção técnica, dos processos operatórios e da transformação da matéria, aspectos que são todos mais facilmente susceptíveis de apresentação museográfica. Pode-se comparar também a importância que tinha a etnotecnologia, sem dúvida um dos pontos fortes dos três mosqueteiros (que, como deve ser, eram na realidade quatro) que criaram o Museu Nacional de Etnologia, com o seu estatuto hoje residual na disciplina.

O desconforto pode ter raízes mais profundas. Para alguns, o museu etnográfico parece nunca poder limpar-se da poeira temática, epistemológica, ética e estética que acumulou durante o longo reinado do seu modelo clássico, e portanto nunca poder libertar-se do risco de produzir representações mais ou menos reificadas e essencializadoras. Muitos duvidam da possibilidade de encontrar um ponto de equilíbrio, inteligível por parte do público não especialista, entre a transmissão de algum saber acerca de uma alteridade cultural, o deleite estético, a análise reflexiva das relações entre o Ocidente e o resto do mundo (ou entre os mundos urbano e rural) que informaram a constituição das colecções e lhes deram o seu significado profundo (de l'Estoile 2007: 423). Outros, que se envolveram em projectos de iniciativa local, podem ter achado muito difícil conciliar as suas posições científicas com as expectativas dos seus interlocutores: responsáveis institucionais, políticos, populações... É que a fase de radical crítica interna da antropologia e da etnomuseologia deu-se exactamente ao mesmo tempo que o crescimento do interesse das populações pelo museu etnográfico. E a disciplina parece ter muitas dificuldades em admitir que, como dizem Christoph Brumann ou Marshall Sahlins, "as pessoas querem cultura" e que a querem precisamente da maneira delimitada, reificada, essencializada e atemporal que as ciências sociais hoje em dia em geral rejeitam (Sahlins 1999). Um colega confiou-me assim que, quanto a ele, chegava por vezes a pensar que não se importaria de queimar todos os museus etnográficos, mas que sabia que, com todo um conjunto de iniciativas patrimoniais cuja ideologia lhe parece eminentemente criticável, representam uma das poucas possibilidades de emprego para os seus estudantes.

Largamente partilhado, o sentimento de inevitabilidade desta realpolitik pode explicar uma parte da ambiguidade com que muitos antropólogos consideram hoje os museus, sem dúvida alimentada também pela frequente constatação da sua incapacidade para orientar a museologia de uma maneira mais adequada às suas posições científicas. Agora intensivamente treinados para a desmontagem de "invenções de tradições", e por vezes fascinados por esta noção até ao ponto de dar a impressão que pensam que a sua mobilização chega para 
perceber qualquer dinâmica cultural, só podem ser reticentes perante uma instituição e um tipo de actividade que muito dificilmente, embora de maneira variável consoante os temas tratados, pode evitar algum grau de reificação. Entre nós, esta reticência diz sobretudo respeito à participação em iniciativas de escala reduzida, por exemplo municipal. Esta situação pode trazer consigo a suspeita de uma cedência a uma certa rusticidade epistemológica, em resultado do envolvimento dos investigadores na rede de interesses e de relações interpessoais locais, e em resposta às expectativas de financiadores que não se satisfariam com algumas elaborações umbiguistas mais ou menos sofisticadas acerca das dúvidas existenciais de antropólogos agoniados pela sua incapacidade de representar, horresco referens, o que é percebido e vivido localmente como uma "cultura" e como "tradições".

Tem que se precisar que, pela expressão "interesse das populações pelo museu etnográfico", usada acima, deve entender-se sobretudo "interesse pelos museus locais", preocupados pelo que se apresenta como "identidade". $\mathrm{Na}$ Europa ocidental, as grandes instituições etnográficas antigas podem também estar viradas para a produção de um discurso acerca da "alteridade", mas em todos os casos, com a excepção de ocasionais exposições, raramente atraem multidões. Nada permite saber para já qual é a parte do efeito mediático na alta frequentação do Musée du Quai Branly desde a sua abertura em Junho de 2006. Na sua contribuição, elaborada a partir da sua experiência como director do Museu de Antropologia da University of British Columbia, em Vancouver, Anthony Shelton contesta a pertinência da noção de "localidade", e mesmo de qualquer escala de referência espacial, para a observação da actividade dos museus, de maneira a evitar uma limitação do olhar a estreitos estudos de casos. Convincente relativamente aos museus da Costa Oeste do Canadá, a sua argumentação não pode fazer esquecer as especificidades vincadas destas instituições: localização num hot spot antropológico frequentado desde os primórdios da época clássica da disciplina, terreno de elaboração de algumas das suas obras mais discutidas (nem que seja só a propósito do potlatch, da estética ou da análise estrutural dos mitos...); poder económico e consciencialização política das comunidades ligadas aos museus; existência, entre elas, de um metadiscurso cultural partilhado e de fortes reivindicações político-culturais; enquadramento num contexto cidadão e académico em que a negociação acerca da definição da investigação está instituída; estatuto de excelência e visibilidade mundial do museu da universidade; descentralização da gestão e da estratégia científica das grandes instituições, nas quais o board tem um papel preponderante... Tudo contribui para fazer com que o "local" dos museus da região tenha uma dimensão muito diferente do que será o caso com, digamos, uma colecção visitável de lenços de namorados algures nas serras do concelho de Vila Verde. Não será preciso insistir no facto de que, numa análise distanciada, o local apresentado localmente enquanto tal nunca pode obviamente ser 
tomado como referente único. A produção da localidade é eminentemente plural, e o local não é simples (Appadurai 1995). No entanto, as ciências sociais podem repetir ad nauseam que as tradições não são o que parecem, que as raças não existem, que as identidades são fluidas, que o local é diluído, nada impede as certezas em contrário de terem uma notável operatividade no mundo social em que os etnógrafos instalam os seus terrenos e os seus projectos museográficos, e onde estão portanto confrontados com a necessidade de encontrar o ponto certo entre cedências e condescendência.

As contribuições de Clara Saraiva e de Jože Hudales ilustram este ponto. Os casos que apresentam são de natureza diversa: projectos estritamente pré-definidos ou não antes da intervenção do etnógrafo, enquadramento institucional, elaboração numa tabula rasa ou no seguimento de projectos anteriores falhados, expressão de pedidos institucionais explícitos ou simples articulação com os desejos informais das populações... Em todos os casos, o sucesso passa sempre pela flexibilidade e por negociações, mais ou menos assumidas enquanto tais, que atribuem algum espaço para a expressão dos sentidos locais. Se, idealmente, o museu deve ser um instrumento de mediação, este seu papel só pode começar com a mediação entre as formas e as instâncias de poder envolvidas na sua elaboração, entre visões e vivências divergentes do saber, dos seus processos e da sua matéria.

No texto que Anthony Shelton discute no dossiê, James Clifford (1997) considera que, no caso da Colúmbia Britânica, os museus "locais" ou "tribais" constituem propostas muito mais arrojadas e "radicais" do que as instituições que qualifica de "maioritárias", vistas como menos inovadoras. No caso da Europa, tal dicotomia não parece observável. Não cabe explorar aqui as profundas diferenças entre dois contextos políticos, académicos e culturais que resultam nesta divergência no que diz respeito à localização (objectiva ou representada) da experimentação ou mesmo da simples competência básica. É mesmo possível que uma maioria de antropólogos europeus considere que os grandes museus ${ }^{1}$ concedem maior liberdade científica, precisamente porque as suas acções escapam aos constrangimentos locais.

Tal pode ser verdade no que diz respeito a exposições particulares, consideradas uma a uma. Mas as grandes instituições, praticamente todas públicas na Europa, não podem no entanto escapar a outras condicionantes, porventura de muito maior vulto e que dizem respeito ao enquadramento ideológico dos seus objectivos e à definição política das suas funções. As acesas e prolongadas polémicas que rodearam a transformação do Musée de l'Homme, a extinção do Musée des Arts et Traditions Populaires (Segalen 2005), a criação do Musée

I O simples critério do tamanho, embora em parte relativo, parece aqui mais pertinente e, em todo o caso, mais objectivo do que o da posição numa escala de avaliação do carácter minoritário ou maioritário dos museus, desde os "tribais" até aos "maioritários". 
do Quai Branly e do Musée des Civilisations de l'Europe et de la Méditerranée (ver o artigo de C. Bromberger) indicam qual é a realidade do poder simbólico dos antropólogos, mesmo quando se trata de delimitar e defender o seu próprio campo de competência. Benoît de l'Estoile mostra bem como, no caso do Quai Branly, a emergência da noção de "arts premiers", estetizante e cheia de boa consciência, a partir do universo dos comerciantes de arte reforçados pelo apoio directo do Presidente da República, atribui na instituição um lugar central a novos especialistas, sobretudo historiadores da arte, e deixou à antropologia um papel de "ciência auxiliar do mercado da arte e do deleite estético". Resta à disciplina tentar agora aproveitar as dinâmicas suscitadas pelo processo de transformação para conseguir a sua recomposição numa instituição que já não domina (de l'Estoile 2007: 282-287, 416-418). Quanto à substituição do Museo Nacional de Antropología pelo Museo del Traje (talvez mais adequadamente designado como museu da moda), em Madrid, é um outro exemplo da fraqueza dos antropólogos quando têm que entrar em confrontação directa com o poder político, mesmo contando com o apoio de um abaixo-assinado internacional com mais de mil assinaturas (Barañano e Cátedra 2005). Um facto é inegável: a por vezes baixíssima frequentação fornece um potente argumento aos promotores de reformas radicais.

\section{BRANDOS COSTUMES}

Sem entrar em considerações abusivamente culturalistas acerca das modalidades do debate público, o facto é que em Portugal, nos últimos anos, a situação da etnomuseologia tem sido desprovida de sobressaltos. Nada de polémicas comparáveis com o que aconteceu em França e em Espanha. O que temos tido de mais parecido, mas que na realidade poderá ter passado despercebido a muitos colegas, foi a discussão acerca do destino dado pelo Ministério da Cultura ao Museu de Arte Popular, fechado desde 1999. O edifício, construído para a Exposição do Mundo Português de 1940, será preservado enquanto importante testemunho da arquitectura do Estado Novo. As colecções devem passar para o Museu Nacional de Etnologia, que acolheu favoravelmente esta ideia, permitindo a abertura, no decorrer de 2008 , de um novo museu dedicado à "importância da língua portuguesa no mundo" e à história dos Descobrimentos. Independentemente do que se pode achar da ideologia deste projecto, que não cabe aqui analisar, deve-se assinalar que algumas vozes se levantaram no seio da comunidade antropológica para protestar contra o encerramento do Museu de Arte Popular, considerando que, além do edifício, tinha de se preservar o seu projecto e o tipo de olhar que propunha sobre a "cultura popular". O argumento da racionalização económica terá sido determinante na decisão de não optar pela possibilidade, algo desconcertante, de musealição de um museu, embora seja por outro lado possível interrogarmo-nos acerca do facto 
de os avultados investimentos necessários para o novo projecto terem sido considerados prioritários quando instituições existentes se confrontam com restrições orçamentais.

No microcosmo antropológico nacional, o debate sobre esta questão foi praticamente inexistente. No entanto, esta decisão do Ministério do Cultura está "impregnada de grandes potencialidades, podendo transformar-se mesmo num elemento dinamizador de valiosos acervos etnográficos que há décadas carecem de soluções apropriadas" (Marques 2006) por pertencerem a instituições actualmente fechadas (o Museu de Etnologia do Porto), sem vocação directa para o seu adequado tratamento museológico (o Instituto de Investigação Científica Tropical), ou cuja ligação com a etnografia é hoje meramente histórica (o Museu Nacional de Arqueologia, detentor da colecção etnográfica do seu fundador, José Leite de Vasconcelos). Falta saber que tipo de intervenção permitiria a conveniente redinamização global e coerente dessas colecções no âmbito de uma política etnomuseológica nacional: não tem que se equacionar unicamente a sua concentração no Museu de Etnologia. Pode sobretudo ser mais realista e estratégico, no actual contexto institucional e financeiro, preocuparmo-nos primeiro com este último museu.

Quando descobri a antropologia portuguesa, há mais ou menos vinte anos, "o Museu" era o ponto de referência, sempre evocado com um misto de respeito e de carinho, o que não impedia uma ocasional crítica. Era o sítio pelo qual passava de facto, directa ou indirectamente, uma parte considerável da investigação antropológica nacional. Longe de ser um mausoléu, era também um lugar de encontro e de algum convívio enquanto se gozava o fabuloso panorama oferecido pelas janelas da biblioteca. Quaisquer que sejam as obviamente múltiplas razões para tal, o facto é que o museu perdeu esta centralidade e parece ter desistido de ter um papel dinamizador da pesquisa.

Existe agora sem ligação com a imensa maioria dos antropólogos trabalhando em Portugal. Não seria por si só desastroso (a investigação encontrou entretanto outros eficazes lugares de acolhimento, no entanto desprovidos de belas vistas sobre o Tejo) se não fosse o facto de se encontrar em hibernação o gigantesco trabalho proporcionado e exigido pelo fabuloso acervo de etnografia portuguesa recolhido principalmente pela equipa de Jorge Dias: Ernesto Veiga de Oliveira, Fernando Galhano e Benjamim Pereira, sem esquecer Vítor Bandeira para a maior parte das colecções exóticas. O leitor poderá talvez pensar que é de uma maneira excessivamente encantatória que textos falando da etnografia portuguesa na segunda metade do século XX evocam estes nomes, mas o facto é que, quaisquer que sejam as possíveis ressalvas teóricas que nos possam ocorrer com o recuo de muitos anos e num contexto sociopolítico profundamente diferente, protagonizaram uma acção etnográfica e museológica que nunca será suficientemente enaltecida, não só pelo seu intrínseco valor 
científico e cultural e o seu carácter pioneiro, mas também por ser um modelo de curiosidade humanista e de abertura humana.

De facto, desde as duas notáveis exposições do Voo do Arado e do Fado - Vozes e Sombras, há mais de dez anos, o museu não realizou nenhuma intervenção de vulto acerca da realidade portuguesa. Limitado por estreitos constrangimentos financeiros e em recursos humanos (que resultaram em Fevereiro de 2007 no encerramento das galerias da Amazónia e da Vida Rural), parece capaz de reagir sobretudo a estímulos exteriores, acolhendo exposições de passagem, em geral de boa qualidade mas cuja variedade em termos de referentes geográficos e culturais não permite apreender uma lógica científica coerente, tornando ainda mais patente a ausência de um necessário discurso problematizado sobre Portugal, como observa justamente Luís Marques (2006) num artigo publicado no diário Público. A este propósito, o museu poderia ter aproveitado melhor nos últimos anos a colaboração de Benjamim Pereira. Artesão de uma grande parte da constituição das colecções, conhece portanto melhor do que ninguém cada peça e a sua história, pessoal e intransmissível a não ser pela voz dele, e realizou intervenções museológicas recentes (como o Museu da Luz) que comprovam a contínua acutilância do seu olhar.

Este último ponto serve para indicar que, na ausência de uma política etnomuseológica nacional, e com uma simples e pouco dispendiosa união de esforços com o grande número de investigadores e de intervenientes que se encontram no terreno, o museu poderia também desempenhar um papel formador, coordenador e orientador da proliferação de projectos museológicos (limitados neste caso à sua vertente etnográfica) que, como vimos, se está a produzir no país. Cheias de boas intenções, estas iniciativas, além de uma frequentemente débil sustentabilidade, padecem de uma repetitividade que se torna rapidamente cansativa, como aponta Christian Bromberger no seu artigo. É assim que um cidadão inglês classifica os museus de província portugueses como clogs museums (museus de socos) porque "todos mostram um par de socos como objecto muito típico e representativo da identidade" de cada terra (Alpuim 2007: 178, nota 28). Um mínimo de coordenação não seria benéfico, por exemplo face ao surpreendente fervilhar de grandes e pequenos projectos de museologia molinológica? Não seria uma maneira de obstar à total falta de estratégia museológica regional observável por exemplo no Minho (Alpuim no prelo)? Além de uma racionalização dos recursos e de uma melhoria da sustentabilidade, seria também uma oportunidade para proporcionar uma aproximação ao mesmo tempo interventiva e reflexiva ao desejo de museu e ao desejo de etnografia que parecem mais fortes do que nunca entre a população do país. Em Ponte de Lima, é pelo menos às centenas que, todas as semanas, após o sarrabulho dominical, os passeantes visitam o Museu Rural, centrado sobretudo na trilogia mais emblemática da antiga agricultura minhota (o linho, o vinho, o milho). Para um olhar etnomuseológico profissional, o acervo é 
fraco e a museografia paupérrima. Mas basta uma breve permanência na sala para perceber até que ponto a exposição fala aos seus visitantes, suscita as suas reacções, activa um vivo sentimento de pertença e de partilha.

No entanto, o público não envereda mais do que os investigadores pelo caminho do Museu de Etnologia. Os dados acerca das entradas (http://www. ipmuseus.pt/pt/museus/M24362/TA.aspx) indicam para os últimos anos uma estabilização à volta de 11.000 (das quais seria interessante saber quantas correspondem ao público escolar), aproximadamente no nível de 1996, antes de uma descida conjuntural ocasionada por obras que não tiveram no entanto nenhum impacto em termos de frequentação. A sua localização em Belém será a única explicação do facto de o Museu de Etnologia não conseguir encontrar um público à altura das suas potencialidades? Sem cair num preguiçoso e perigoso populismo metodológico, não temos que considerar que o sucesso de realizações amadoras, diletantes, naïves, questiona alguns dos nossos pressupostos e das nossas práticas?

\section{ETNOMUSEÓLOGOS DE TODOS OS PAÍSES...}

É a partir das constatações e interrogações apresentadas nas páginas anteriores que se constituiu a ideia de realizar um seminário, co-organizado pelo Institut d'Ethnologie Méditerranéenne et Comparative e pelo Centro de Estudos de Antropologia Social em Aix em Provence, em 6 de Abril de 2007. Parte da motivação veio também de uma pequena irritação perante o gigantesco corpus, em crescimento permanente, produzido na intersecção das áreas da museologia e dos museum studies, e que, talvez erradamente, me transmite a impressão de estar muitas vezes bastante desligado das realidades do terreno. Sem negar a possibilidade de compreender a partir de uma posição exterior (seria o cúmulo, por parte de um antropólogo), a ideia é portanto aqui dar a palavra a antropólogos envolvidos pessoalmente em projectos concretos. As suas contribuições constituem o dossiê apresentado neste número da Etnográfica. Os prazos de realização da revista não permitiram a inclusão de um quinto texto, apresentado no seminário por André Julliard, que, entre todos os participantes, era provavelmente o que iniciou uma colaboração com um projecto museológico a partir de uma posição mais reticente e retraída. Ora, precisamente, através da apresentação de uma variedade de casos que alcançaram uma certa visibilidade e relevância em diversos países (e sem obviamente aspirar a uma exaustividade inatingível mesmo no caso do relativamente reduzido universo português), o objectivo era mostrar como é que esses investigadores acomodam as suas expectativas às das populações ou das instituições que, por vezes, recorrem a eles. Para que desenvolvimentos conduzem estas negociações? Que considerações teóricas podem decorrer da confrontação com os constrangimentos do terreno? Ao mesmo tempo polimorfo e enquistado em 
representações ultrapassadas, hesitante perante a multiplicidade das vias que se apresentam agora a ele, o museu pode aparecer como o obscuro objecto do desejo etnográfico. Espera-se que o dossiê contribua para mostrar que, mesmo indefinido, elusivo, provocante, irritante, insatisfatório, o museu etnográfico não tem que frustrar sempre todos os desejos que atrai.

Observar a etnomuseologia contemporânea leva a desejar uma abordagem reflexiva mais crítica da maneira por vezes demasiado despreocupada com a qual os antropólogos integram na sua actividade as premissas da ideologia conservacionista hoje hegemónica. A actual vertigem patrimonializadora fornece oportunidades de financiamento, mas nem deveria ser preciso lembrar que tem implicações insustentáveis quando é aplicada a uma matéria viva e dinâmica. Beijo que mata as realidades que pretende preservar, a museografia de luvas de algodão branco, rigorosamente respeitadora dos seus preceitos metodológicos e técnicos, pode não ser a mais adaptada a pelo menos certos ramos da etnomuseologia. Já se fez a contestação das modalidades expositivas da museografia clássica, aliás por vezes de maneira excessiva em razão do peso da ortodoxia que foi preciso abanar. É preciso agora reavaliar os objectivos de museus concebidos inicialmente mais ou menos em função de preocupações de uma etnografia de urgência que já não pode ser a nossa única motivação. A maior parte dos grandes museus, enfrentando nomeadamente todos os problemas levantados pela musealização dos objectos do nosso quotidiano, já se estão a debruçar sobre a questão. Mas os investigadores presentes no terreno têm a possibilidade de articular esta reflexão com os projectos locais em que participam. O desejo de reificação cultural com que em geral estes nos confrontam é tão forte que a contestação da ideologia patrimonializadora não será fácil (tanto mais que o "património" já se tornou um potente instrumento político). Mas este esforço, que exigirá muita imaginação e negociação, proporcionaria uma real possibilidade de renovação da abordagem etnomuseológica: esta passaria a ser definida em primeiro lugar menos relativamente à sua função de conservação com uma ancoragem territorial e cultural delimitada, mas sim enquanto intervenção e crítica cultural aplicadas a temáticas relevantes. Os seus momentos, lugares e formas poder-se-iam então diversificar muito.

O desejável novo modo de relacionamento entre a sociedade e os museus tem também uma dimensão mais institucional, assunto que ultrapassa obviamente em muito a área da etnomuseologia. Quaisquer que sejam os desenvolvimentos futuros do seu financiamento público, todos eles, públicos e privados, têm agora que repensar os seus recursos financeiros, sendo muito raros os que têm a possibilidade de implementar um merchandising a partir de alguns dos seus objectos ou das suas competências e da sua "marca". Goste-se ou não da ideia, o recurso ao mecenato parece ser uma inevitabilidade a curto prazo. Além de, mais uma vez, não ser uma solução para todos, terá consequências que se deve equacionar. A mais óbvia prende-se com a (justa) reivindicação, 
por parte dos dadores, de participação na definição da actuação do estabelecimento que ajudam, o que torna necessária a instalação de um órgão do tipo do board dos grandes museus privados. É aliás possível pensar que, mesmo num contexto de financiamento público dos museus nacionais e sem prescindir da prerrogativa política da nomeação dos seus directores, a introdução de um conselho de orientação científica e estratégica seria benéfica. Além de limitar o risco, sempre existente, de ver um responsável por um museu entrincheirar-se nas suas reservas como um rato no seu queijo e tentar limitar o acesso a colecções públicas como se fossem o seu tesouro pessoal, poderia ser (consoante as suas regras de composição e de designação) um factor de democratização e de transparência. Além disso, e sobretudo, quando a área de competência de um museu corresponde exactamente a um domínio do saber académico institucionalizado, do qual é forçosamente uma das manifestações mais visíveis no plano nacional, a existência de semelhante órgão seria uma maneira de assegurar a qualidade da articulação entre a instituição e a comunidade dos investigadores. Tal parece especialmente importante quando uma disciplina (como é, por exemplo, o caso da antropologia hoje em dia) já não está orientada por um paradigma dominante e por preocupações homogéneas.

Esta heterogeneidade é uma das causas da fragmentação e da pluralidade da realidade etnomuseológica. Estas devem ser tomadas como um fortíssimo incentivo para uma inventividade mais assumida, um trunfo para que seja possível evitar a emergência de uma qualquer nova hegemonia discursiva. Só assim será possível fazer com que todos sintam novamente, como Tintim e Milou, o desejo de correr, depressa, para o museu etnográfico e desvendar o mistério da vertiginosa capacidade humana para a diferenciação cultural.

\section{BIBLIOGRAFIA}

ALPUIM, João M.A.C.B., 2007, Panorama Museológico do Alto Minho, tese de mestrado em Museologia e Património, Universidade Nova de Lisboa.

—, no prelo, "O 'boom museológico' no Alto Minho em final do século XX - início do XXI”, in Manuela Cunha, e Luís Cunha (eds.), Intersecções Ibéricas: Margens, Passagens e Fronteiras. Lisboa, 90 Graus Editora.

APPADURAI, Arjun, 1995, "The production of locality", in R. Fardon (ed.), Counterworks. Londres, Routledge. 
BARAÑANO, Ascensión, e María Cátedra, 2005, "La representación del poder y el poder de la representación: la política cultural en los museos de Antropología y la creación del Museo del Traje", Política y Sociedad, vol. 42, n. ${ }^{\circ} 3$.

BROMBERGER, Christian, 1997, "L'ethnologie de la France et ses nouveaux objets. Crise, tâtonnements et jouvence d'une discipline dérangeante", Ethnologie Française, n. ${ }^{\circ}$, 1997.

— récente de l'ethnologie de la France”, in Chiva I. e Jeggle U. (eds.), Ethnologies en Miroirs. La France et les Pays de Langue Allemande. Paris, Éditions de la Maison des Sciences de l'Homme.

CLIFFORD, James, 1997, Routes. Travel and Translation in the Late Twentieth Century. Cambridge, MA, Harvard University Press.

De L'estoile, Benoît, 2007, Le Goût des Autres. De l'Exposition Coloniale aux Arts Premiers. Paris, Flammarion.

DIAS, Nélia (ed.), 1997-2001, Roteiro de Museus (colecções etnográficas), 5 volumes. Lisboa, Olhapim Edições.

INSTITUTO PORTUGUÊS DE MUSEUS, http://www.ipmuseus.pt/pt/museus/M24362/TA.aspx (consultado em 10 de Outubro de 2007).

HERGÉ, 1947 (1938), L'Oreille Cassée. Tournai, Éditions Casterman.

KROEBER, Clifton, e Karl Kroeber (eds.), 2003, Ishi in Three Centuries. Lincoln, University of Nebraska Press.

MARQUES, Luís, 2006, "O Museu de Arte Popular e a perspectiva antropológica”, Público, 23 de Novembro de 2006.

MINOM, http://minom-icom.net/PDF/Reglementsgeneraux.pdf (consultado em 10 de Outubro de 2007).

SAHLINS, Marshall, 1999, "Two or three things that I know about culture", The Journal of the Royal Anthropological Institute, vol. 5, n. ${ }^{\circ} 3$.

SCHEPER-HUGHES, Nancy, 2001, "Ishi's brain, Ishi's ashes. Anthropology and genocide", Anthropology Today, vol. 17, n. ${ }^{\circ} 1$.

SEGALEN, Martine, 2005, Vie d'un Musée, 1937-2005. Paris, Stock. 